\title{
Hydrogel-based delivery for antineoplastic drugs and vascular scaffolding.
}

Adelaide Iervolino ${ }^{1}$, Camilla Chello ${ }^{2}$, Massimo Chello ${ }^{3}$ and Francesco Nappi ${ }^{4}$

${ }^{1}$ Department of Cardiovascular Sciences, Fondazione Policlinico Universitario A. Gemelli IRCSS, 00168 Rome, Italy; adelaide.iervolino@libero.it

${ }^{2}$ Regenerative Medicine, Università Campus Bio-Medico di Roma, 00128, Rome, Italy; camilla.chello@gmail.com

${ }^{3}$ Cardiovascular surgery, Università Campus Bio-Medico di Roma, 00128, Rome, Italy; m.chello@unicampus.it

${ }^{4}$ Centre Cardiologique du Nord, Department of Cardiac Surgery, 93200 Saint-Denis, France; francesconappi2@gmail.com

*Correspondence: francesconappi2@gmail.com; Tel.: +33-149-334-104; Fax: +33-149-334-119

\begin{abstract}
:
Hydrogels, hydrophilic polymeric compounds, have been recently put under investigation as regenerative medicine applications and delivery systems for antineoplastic drugs, particularly chemotherapeutics (anthracyclines, alkylating agents), target drugs (trastuzumab) and immunotherapies. Porosity, conductivity, biodegradability and physical states are some of the peculiarities that render hydrogels suitable for therapies implementation. Chemically-modifying agents and enzymes can be also coupled to hydrogels for pharmacokinetical parameters improvement and side effects avoidance. Cardiotoxicity is in fact one of the major issues for oncological patients after treatment efficacy. Heart failure, myocarditis and hypertension are causes of morbidity and mortality that can possibly be avoided. Specific reaching of the target tumor site has been achieved by several authors in preclinical in vivo studies but clinical
\end{abstract}


studies are currently under design processes. Polydioxanone, a hydrogel-mimicking agent, is capable to interact with the elastic properties of pulmonary artery. An advantageous characteristic is that can be also reabsorbed within biological systems and can cause a remodeling process of the vessel wall. Hydrogels currently represent a strong topic of interest for researchers and probably will guide future clinical investigations and practice.

Keywords: hyrogel, cardiotoxicity, regenerative medicine, antineoplastic drugs, polydioxanone, pulmonary autograft

\section{Introduction. Preventative strategies for cardiovascular mortality reduction after anticancer therapies}

Cancer survivors carry a high risk of cardiovascular disease development. Mortality rates from cancer have declined over the past years but concerns are rising about cardiac side effects of specific antiancer treatments, namely chemotherapics, target therapies and immunotherapics. Associations between cancer outcome and cardiovascular disease or therapies have been demonstrated by several reports, including the case of hypertension [1]. Braithwaite et al [1] analyzed the incidence among breast cancer patients and reported hypertension as an independent predictor of survival disparity among affected and non affected patients. Also, beta-blockers use was demonstrated to decrease mortality among cancer patients, as reported by various meta-analyses [2].

Cardiotoxicity is a complex challenge, impacting on clinical scenarios, epidemiological data and national heatlh systems costs [3-5]. Following a decade-long period of management approaches and guidelines provision by leading world health societies, present directions orient 
towards optimization of prevention strategies, including delivery systems and polymeric compounds applications. Those elements, integrated or conjugated to potential cardiotoxic drugs are demonstrating beneficial results in conditioning direction of therapeutical molecules and avoidance of off-target side effects [6-8]. Hydrogels are polymeric compounds endowed with favourable tecnichal characteristics. They have been tested in conjugation with several cardiotoxic therapeutical drugs and resulted good delivery strategies to avoid unwanted side effects [9].

\subsection{Regenerative medicine applications}

Regenerative medicine is an emerging field that allows to overcome many limits placed so far in the management and treatment of several diseases [10,11]. In fact, when tissue damage occurs, the standard therapeutical options are limited: materials availability for autologous transplantation is scarce, and the same sampling can create further complications for the patient, while allograft has a high risk of immunogenicity [12]. In particular, thanks to the huge developments of tissue engineering, it is now possible to replace devitalized tissues and organs with functional insufficiency, as well as to transport therapeutic substances and cells in the target area.

The route of administration is usually minimally invasive while ensuring the effectiveness of the transport system [10]. Several elements such as the use of biomimetic materials, which can function as scaffold and cell growth and replication support growth, are necessary, as well as the action of growth factors and bioactive molecules, in order to restore the damaged tissue [13].

Recently, interest in hydrogels, three-dimensional hydrophilic polymeric compounds, has grown. Thanks to the similar structural characteristics to ECM, they represent the ideal tools 
for creating biocompatible scaffolds that can mimic the action of the endogenous matrix, promote cell growth and repair target tissue [14].

\section{Hydrogel-based compounds}

\subsection{Structural attributes and manifacturing dissimilarities}

Hydrogels are three-dimensional, highly hydrophylic polymeric compounds: they are able to absorb a large amount of fluids, mainly water (90-99\%), exchanging oxygen and increasing in volume without altering their composition [14,15]. Morevoer, the high fluid content makes them suitable to absorb and encapsulate cells [10].

Hyrogels were first used by Wichterle and Lim, who developed a cross-linked hydrophilic polymer (2-hydroxyethyl methacrylate) to produce contact lenses [15].

Depending on the composition of the polymers, hydrogels can be classified into: -Homopolymers, if derived from a single monomer species, - Copolymers, two or more monomer species with at least one hydrophilic component, - Multipolymer Interpenetrating polymeric hydrogel (IPN), consisting of two polymers, natural and/or synthetic, crosslinked [16].

Depending on their physical state, hydrogels are distinguished into:

-amorphous,

-semi-crystalline,

-crystalline [16].

Other elements that characterize hydrogels are porosity (size of the pores, distribution), biodegradability, conductivity, density and cross-linking (figure 1) [10,17]. 


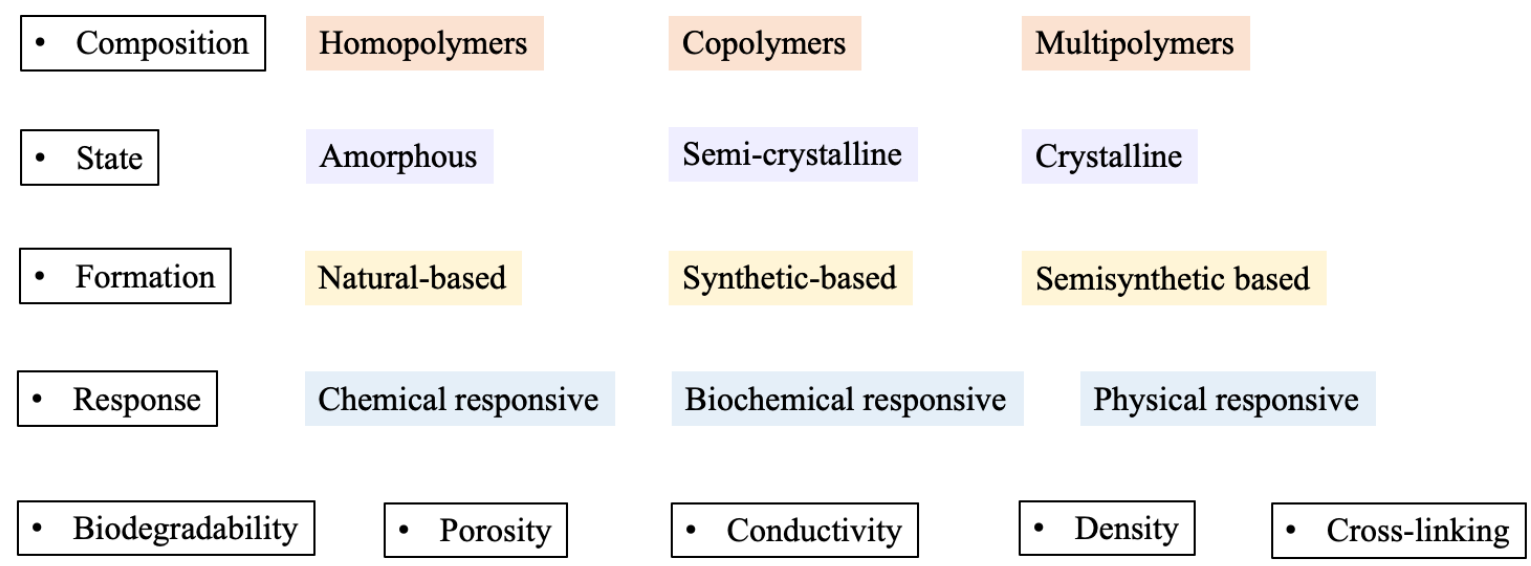

Figure 1. Classification of hydrogels according to their characteristics. Types differentiation is based upon composition, state, formation, response, biodegradability, porosity, conductivity, density and cross-linking.

Combined together, they define structural and biological properties of these compounds.

Porosity, permeability and mechanical properties of scaffolds are important factors that condition cell growth, migration and colonization. The porosity of a scaffold is given by the presence of pores, open and closed, of different sizes, shapes, spatial distribution and interconnection [15]. Therefore, by changing the composition, the density of the cross-linking, the polymerization conditions, and the mechanical properties of hydrogel can be modified [15]. The hydrogel manufacturing process is also important because it will determine its characteristics, such as the size of the pores, their distribution and the forces of coexistence.

On the basis of the composition of hydrogel materials they can be distinguished in naturalbased, synthetic-based and semisynthetic-based [10,16]. In general, synthetic materials are hydrophobic in nature and have a greater mechanical strength that reduces degradability and increases durability of the material [16]. Natural-based hydrogels are usually more biocompatible and biodegradable [18]. They possess peptide sequences that are recognized by membrane receptors, increasing interaction with cells and consequently cell proliferation [18]. The major limitation linked to the use of natural materials is their lack of availability, as well as the poor ability to control degradation $[19,20]$. 
Natural compounds commonly used are fibrin, collagen, hyaluronic acid.

Synthetic- based hydrgels are easy to produce, which results in greater standardization and control of physical characteristics such as conductivity, contractivity, density, porosity [10,21]. However, synthetic materials lack recognizable portions that can develop cellular responses [10]. Synthetic materials can be furhter classified into non-degradable and biodegradable, depending on their ability to maintain intact their physical characteristics or be degraded [10]. Synthetic materials frequently used are lactic acid, glycolic acid [10] and their derivates [22], poly esters and poly urethanes [23].

Among them, poly ethylene-glycols (PEG), stands out for its versatility and extreme biocompatibility [10]. Recently, thanks to the different association between synthetic and natural compounds, semi-synthetic hydrogels have been developed: this combines a good control of the structure of the scaffold and an optimal cellular response, thanks to the presence of natural components $[23,24]$.

\subsection{Smart Hydrogels}

Smart hydrogels are polymers that can change their structural characteristics in response to different types of stimuli [25] and, once the latter has ceased, they are able to return to their equilibrium conditions [26]. These characteristics make this new generation of hydrogels more similar to the extracellular matrix; moreover, the increased controlled response make them suitable for the release of drugs only under certain conditions [10].

Depending on the stimulus, hydrogels can be distinguished into:

- Chemical responsive: $\mathrm{pH}$ and oxidant status changes can alter hydrogel conformation.

However, $\mathrm{pH}$ changes cannot easily penetrate through materials.

- Biochemical responsive: changes are induced by different types of molecules (enzymes, antigens, etc) [10,27]. 
- Physical responsive hydrogel: pressure, temperature, light induce changes in the physical state of hydrogels.

Hydrogels responsive to physical stimuli seem to be the most promising for medical applications, due to the relative ease of handling the physical stimulus. Thermosensisitve hydrogel are the most commonly used in recent years: below a certain temperature in fact, they are in the gel phase, otherwise they are present in liquid solution. Consequently, hydrogels at room and body temperature are ideal for modification in gel state after injection $[10,15]$. The chemical degradation rate of hydrogels can be adjusted by controlling the density of bound networks and enzymatic hydrolysis induced by proteases [15].

\subsection{Nanogel and Microgel}

Hydrogel of microscopic (microgel) and nanoscopic (nanogel) size were created, consisting of polymers of nanoparticles swollen in water that form three-dimensional networks of polymeric chains $[10,28]$. Their small size favours an increased available surface and, consequently, the ability to transport molecules [29]. In addition, the small size allows smart hydrogels to respond more quickly to environmental stimuli, as well as to reach inaccessible body locations. However, nanogels induce a faster and more difficult to control release of drugs than microgels $[10]$.

\section{Hydrogel degradation.}

The physical degradation of hydrogels provides space for cell migration and vascular infiltration in order to regenerate the suffering tissue $[15,30]$. The rate of degradation of hydrogels should therefore match with those of tissue regeneration in order to maintain the integrity of the new tissue and mechanical stability. The degradability of hydrogels depends on different physical factors such as the properties of the materials that contain them as well 
as different environmental factors [15,31].

The possibility of modulation the degradation rate of hydrogels has been also considered in the treatment of wounds with a poor tendency to healing [33]: no removal costs are required, with risk of suffering and, in the case of injuries, bleeding [34,35]. A hydrogel that degrades in coincidence with the wound repair process is able to significantly reduce the discomfort to the patient [31].

\section{Cardiotoxicities from anticancer therapies : prevention and risk reduction}

\subsection{Chemoterapics, target therapies, immune checkpoint inhibitors}

Recently, personalizing treatments with anti-cancer target therapies and immune therapies resulted in survival improvement but cardiovascular adverse effects experienced by an important percentage of patients [36-38]. Regenerative medicine is currently investigating advancements in drug delivery to targets, in order to avoid off-target effects, and strategies, such as cardioprotectants administration where delivery is not an option [39-41]. In particular, cardiotoxocities mainly arise from standard chemoterapics and targeted therapies. Immune checkpoint inhibitors and CAR $\mathrm{T}$ (chimeric antigen receptor $\mathrm{T}$ ) cell therapies consitute the broad group of immunotherapies (table 1) [42]. They tend to cause rarer, but more fatal, cardiovascular events [43,44].

\begin{tabular}{|l|l|l|}
\hline \multicolumn{1}{|c|}{ Antineoplastic drug } & Cardiac manifestations & $\begin{array}{l}\text { Proposed molecular } \\
\text { mechanism }\end{array}$ \\
\hline Doxorubicin/Daunorubicin/Epirubicin & $\begin{array}{l}\text { Left ventricular } \\
\text { dysunction }\end{array}$ & $\begin{array}{l}\text { Oxidatvie stress, } \\
\text { mitochondrial } \\
\text { dysfunction }\end{array}$ \\
\hline Cyclophosphamide & $\begin{array}{l}\text { reduced cardiac } \\
\text { function, pericardial } \\
\text { effusion and decreased } \\
\text { ECG voltage }\end{array}$ & $\begin{array}{l}\text { DNA damage, cell } \\
\text { damage }\end{array}$ \\
\hline
\end{tabular}




\begin{tabular}{|l|l|l|}
\hline 5-fluorouracil/capecitabine & $\begin{array}{l}\text { ischemia, pericarditis, } \\
\text { HF }\end{array}$ & $\begin{array}{l}\text { DNA damage, } \\
\text { oxidative stress }\end{array}$ \\
\hline Trastuzumab/Pertuzumab (antiHER2) & $\begin{array}{l}\text { left ventricular } \\
\text { dysfunction, arrhythmias }\end{array}$ & antagonism of HER2 \\
\hline Bevacizumab & $\begin{array}{l}\text { hypertension, } \\
\text { thromboembolism }\end{array}$ & antagonism of VEGF \\
\hline $\begin{array}{l}\text { Nivolumab/Pembrolizumab/Atezolizumab } \\
\text { (Immune checkpoint inhibitors) }\end{array}$ & Fatal myocarditis & under investigation \\
\hline
\end{tabular}

Table 1. Major cardiotoxicity-causing antineoplastic drugs are tabulated. Cardiac manifesttaions and hypothesised mechanisms for cardiotoxicity development are dysplayed in each row. Abbreviations. ECG: electrocardiogram, HF: heart failure, HER2: human epidermal receptor 2, VEGF: vascular endothelial growth factor.

Vascular changes are mainly caused by alkylating agents, antimetabolites, microtubule binding agents, platinum agents, mainyl cisplatin and antibiotics. They are also responsible for hypertrophic and dilated cardiomyopathies development. Pericardial diseases can be either caused by antimetabolites, in particular cytarabine, and immune therapies, mainly immune checkpoint inhibitors $[45,46]$. Arrythmias generation is a rising adverse effect from conventional therapy, such as alkylating agents, microtubule binding agents and immunomodulatory drugs. Target therapies also have a role in arrhythmia generation: mTOR (mechanistic target of rapamycin) inhibitors, BCR-ABL1 (Breakpoint Cluster Region-ABL1) inhibitors, BTK (Bruton's tyrosine kinase) inhibitors, ALK (Anaplastic lymphoma kinase), BRAF (Rapidly Accelerated Fibrosarcoma-B) and MAPKK (Mitogenactivated protein kinase kinase) inhibitors [47-50]. Immune checkpoint inhibitors and CAR $\mathrm{T}$ cell therapies mainly cause fatal myocarditis, Takotsubo syndrome, acute cardiovascular syndromes and perciardial diseases. Mainly diagnosed by electrocardiography and echocardiography, these entities represent an important 
burden for oncological patients, requiring therapy suspension and invasive diagnostic/therapeutical strategies of management.

\subsection{Anthracycline-induced cardiac diseases}

Doxorubicin, an antineoplastic anthracycline antibiotic [51], was first discovered to cause heart failure in 1970s [52]. Adryamicin-treated cancer patients were evaluated during serial followups. Diagnostic electrocardiograms (ECGs) revealed significant QRS voltage decrease while echocardiographies revealed ventricular systolic failure, atrial dilation and other paramteric changes in 44 (11\%) of total 399 patients [52]. Refractoriness to inotropic drugs and mechanical ventricular assistance was also clinically reported.

Left ventricular dysfunction is the most common cardiac side effect caused by doxorubicin. Alteration of topoisomerase $\mathrm{IIb}$ and reactive oxygen species generation are some of the responsible mechanisms. One of the risks associated with drug exposure is the late development of cardiac disfunction. A potential $20 \%$ of patients is estimated to be diagnosed after chemotherapy completion [53-55].

The major risk factors for cardiotoxicity development are cumulative high doses, old age or young age, concomitant administration of other cardiotoxic drugs, radiation therapy exposure and cardiovascular diseases [56,57].

\subsection{Alkylating agents and selected target therapies}

Administration of cyclophosphamide, an antineoplastic agent used in combination with stem cell transplant, has been associated to reduced cardiac function, pericardial effusion and decreased ECG voltage [58-60]. It also causes hemorragic myopericarditis and complications, such as pericardial effusion. 
Trastuzumab instead is broadly identified as a target agent, used for breast cancer and stomach cancer being it a monoclonal antibody against HER2 [61,62]. Adverse effects involving cardiac tissue from trastuzumab are mainly represented by cardiac dysfunction and alteration of echocardiographic parameters $[63,64]$.

A preclinical study demonstrated that HER-2 is expressed in myocardiocytes of embryonic wild-type mice with a distribution pattern that is mostly restricted to the T-tubular network [65]. Instead, conditional mutant mice with cardiac-restricted HER-2 deletion showed dilated cardiomyopathy development after birth [65]. Although the role of HER-2 has not been completely unrevealed, several studies demonstrated that it is involved in cardiac hypertrophy as compensatory mechanism [65].

\subsection{Strategies for specific drug delivery}

Several delivery approaches have been developed for tumor targeting in preclinical studies. Doxorubicin is now preferentially administered as pegylated liposomal doxorubicin to patients suffering from ovarian cancer, multiple myeloma, Kaposi sarcoma and others. It has been repeatedly investigated for specific tumor targeting in conjugation with hyper branched polymers or metronomic nano delivery. Results from clinical studies showed significant reductions in tumor size $[66,67]$.

Anthracyclines have represented an important cause of morbidity and mortality in cancer survivors by causing cardiomyopathy, heart failure and even cardiac death. Reponsible mechanisms were identified in oxidative stress generation, defective mitochondrial biogenesis and consequent myofibrillar disarray and vacuolization [68]. Rising cardiac troponins T levels are expected in cardiotoxicity cases. Recently, the use of exosomes in conjugation to doxorubicin demonstrated to reduce the drug cardiac concentrations by $40 \%$ [69]. 
Adeno associated viruses were also tested for delivery of bevacizumab and other anti-VEGF antibodies. Bevacizumab was particularly tested for glioblastoma multiforme in preclinical studies [70]. Hicks and colleagues specifically delivered AAVrh.10BevMab, an AAVrh.10based vector coding for bevacizumab to NOD/SCID immunodeficient mice, finding reduced tumor volumes and decreased angiogenesis. Quantitative PCR, ELISA and western blotting demonstrated localized tissue expression of bevacizumab. Immunohistochemistry was instead used for neurons expression. Authors concluded that, due to an increased survival, results signifiy an efficient drug passage through the blood-brain barrier [70].

Anti-VEGF A antibodies were also expoilted in combination with adenoviruses. Patients in metastatic setting, suffering from lung cancer, were administered with AAV (adeno-associated virus) vector AAVrh.10alphaVEGF expressing an anti-VEGF A antibody equivalent to bevacizumab [71]. The adenoviral vector encoded the light chain and heavy chain complementary DNAs of monoclonal antibody A.4.6.1, a murine antibody that specifically recognizes human VEGF-A with the same antigen-binding site as bevacizumab [71].

After intrapleural administration, authors demonstrated a significant suppression of tumor growth, a decrease in the number of blood vessels and mitotic figures and increased animal survival [71].

\section{Hydrogel-based applications in preclinical studies}

\subsection{Trastuzumab therapy}

Cardiotoxicities from trastuzumab and reduced penetration of the monoclonal antibodies in tumors has led investigators to develop strategies of tecnical improvements. The tumor microenvironment is in fact composed by extraceullular matrix (ECM) and high interstitial fluid pressure (IFP) [72,73]. Interestingly, intravenous injection of trastuzumab has registered low therapeutical concentrations in the target, i.e., less than $0.01 \%$ of the dose per gram of tumor 
tissue $[74,75]$. The co-administration of antibodies and collagenase or hyaluronidase, given that collagen-I is the main component of ECM, is under investigation.

Recently, strategies concerning hylauronidase-incorporated hyaluronic acid-tyramine hydrogels and co-delivery of collagenase has therefore been tested for trastuzumab release. The experimental work by Pan et al [76] investigated a polymer-based thermosensitive hydrogel incoroprating trastuzumab and collagenase. The combination was named Col/Tra/Gel and, once injected into mice models, converted into a drug-loaded biodegradable hydrogel. Both collagenase and Cy7-trastuzumab were released from the hydrogel and the dense ECM was degraded by the collagenase, in order to favour trastuzumab deep tissue penetration. Interestingly, cardiotoxicity was not present in Col/Tra/Gel-treated mice. Two other study groups, namely mice treated with trastuzumab solution for single injection, that was named Tra-Sol single i.v. (intravenous), and trastuzumab solution for multiple i.v. injection, indicated as Tra-Sol multiple i.v. showed significant heart tissue involvement, with cardiotoxic effects involving these two groups. Moreover, flogosis and systemic toxicity were not found in any of the mice treated with hydrogel combinations, even 6 months after treatment completion [76]. Another strategy, formulated for carrying high antibodies loads and providing a sustained release of the target drug, involves the chemical modification of hydrogels structures. A maleimide-modified c-polyglutamic acid (c-PGA-MA) and thiol end-functionalized 4-arm polyethylene glycol (4-arm PEG-SH) was obtained by investigators of the Taipei Medical University [77]. Authors developed a novel approach consisting in subcutaneous injections of trastuzumab coupled with a specific hydrogel formulation, for delivery of high doses of drug (>100 mg/mL). One of the advantages was a sustained release, lasting for several weeks, due to electrostatic interactions and functional characteristics including structural integritiy and binding bioactivity. 
To ensure the antineoplastic effects of the formulation, in vitro studies of anticancer efficacy were performed on human breast cancer cells. Inhibition of proliferation was confirmed and invivo efficacy was tested too, by using a xenograft tumor model. Xu and colleagues [78] also experimented a combination of hydrogel and drug for trastuzumab release, involving hyaluronidase as another component of the formulation. Sustained release was obtained for 4 weeks. Specifically, authors found a reduced tumour size when testing the combination in vivo [78].

\subsection{ICI administration via hydrogels delivery systems}

Immune checkpoint inhibitors have been also tested for specific target delivery via hydrogel formulations. Specifically, injectable polypeptide hydrogels have been tested for delivery of vaccines and checkpoint inhibitors [79]. Therapeutical agents (anti-CTLA-4/PD-1 antibodies) were mixed with tumor cell lysates and GM-CSF (granulocyte-macrophage colony stimulating factor) and tested upon the activity of dendritic cells (DCs) [79]. Results showed a strong Tcell reaction in vivo. Instead, when the hydrogel was coupled with antitumoral vaccines, IgGs production was also upregulated and IFN- $\gamma$, IL-4, and TNF- $\alpha$ levels were increased too [79]. Authors discovered that the hydrogel-based immunotherapy increased $\mathrm{CD}^{+} \mathrm{T}$ cells expression within the spleens and within tumors of vaccinated mice. Also, they were able to reduce the ratio of Tregs.

The research group by Han et al [80] developed a hydrogel for local therapy delivery by $\mathrm{T}$ mixing N1-(4-boronobenzyl)-N3-(4-boronophenyl)- N1, N1, N3, N3-tetramethylpropane-1,3diaminium (TSPBA) with poly (vinyl alcohol) (PVA) [80]. In another work, an anti-PD1 and Zebularine, a cytidine analog recently studied for chemoprevention, were delivered by an in situ formed hydrogel [81]. An enhanced immunotherapeutical response has also been achieved by the development and testing of a reactive oxygen species (ROS)-responsive polypeptide gel 
for facilitation of immune active drugs delivery. Specifically, it was tested in combination with an anti-PDL1 antibody and dextro-1-methyl tryptophan, inhibitor of indoleamine-2,3dioxygenase and facilitator of $\mathrm{T}$ cell proliferation arrest [82]. $\mathrm{Yu}$ et al [82] effectively demonstrated a reduction in local ROS levels and an in vivo increased response to melanoma. Hydrogels have also been studied in combination with immune checkpoints-blocking DNA aptamers. They show advantages over antibodies in thermal stability and immunogenicity [8385]. DNA aptamer hydrogels can be generated through rolling circle amplification (RCA), a tecnique that amplifies and hybridizes template sequences [85]. Results showed in vivo retention of the hydrogel at injection site: two groups were analyzed, a free PD-1 aptamer treated group and a PAH treated group and the latter showed prolonged fluorescence signals after administration. In vivo antitumor effects of the hydrogel combination were also demonstrated and efficacy of liberation of PD-1 aptamers from PAH was tested through splenocytes secretion of interleukin-2 (IL-2) resulting in optimal pharmacodynamical effects [85]. Thus, immune checkpoint inhibitors including aptamers are an emerging therapeutical class possibly showing diminished side effects and increased kinetics parameters thanks to hydrogels development and combined administration (figure 2).

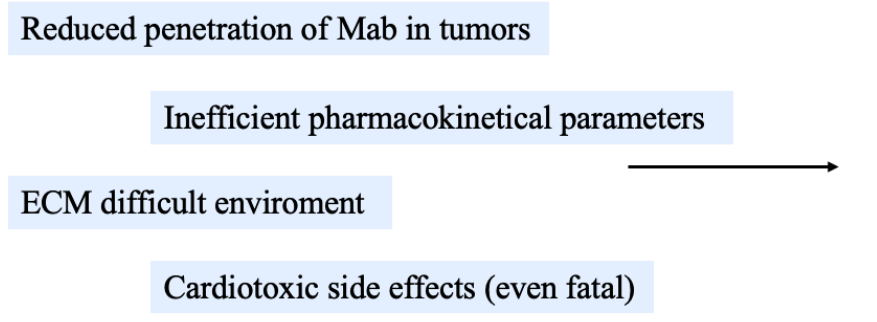

- Hydrogels incorporating ECMmodifying enzymes and trastuzumab

- Chemically-modified hydrogels

- Polypeptide hydrogels with anti-CTLA4/PD-1 antibodies

Figure 2. Chart representing main difficulties in developing antineoplastic monoclonal antibodies (dysplayed in blue) and most relevant tested strategies. Technical advantages achieved after preclinical

Less immunogenicity

More thermostability

Efficient kinetics

Sustained release

Preserved antineoplastic effects 
in vitro and in vivo testing of hydrogels are also represented (in green). Abbreviations. Mab: monoclonal antibodies, ECM: extracellular matrix, CTLA4: cytotoxic T-lymphocyte antigen 4, PD-1: programmed death 1, DNA: deoxyribonucleic acid.

\section{Polyesters that mimic hydrogels: clinical prosthetic use}

Polydioxanone (PDS; Ethicon Inc. Johnson \& Johnson) is a polyester with hydrogel-like characteristics. It can be reabsorbed within biological systems undergoing progressive degradation without this leading to nuanced reactions or toxic effects. These peculiar characteristics have been exploited in our experimental studies to reinforce the pulmonary artery wall [86-88]. The degradation and elimination of polydioxanone was determined by the process of cell phagocytosis, enzymatic degradation and physical dissolution through biological liquids. PDS was used as an external resorbable reinforcement prosthesis and proved to be versatile and to not change its features during the using time. During the period in which the material was inside the vessel wall, from 6 months to 12 months later, the implantation in growing lambs did not evoke any inflammatory reaction requiring its removal. Also, no cases of blood clots were recorded. After complete resorption of the initial implant polyester in the extracellular matrix (ECM), no detrimental histological reactions were noted but a physiological remodeling process in the ECM of the vessel wall was reported [89-93].

PDS a has been shown to be a biomaterial capable of interacting with the elastic properties of the pulmonary artery. Furthermore, a synergy was found between the elastic properties of the PDS and the degradation time that was required once implanted, obviously in accordance with the application for which it was intended. It has been shown to be an ideal polymer with the following biological and mechanical properties [94,95]. As for the biological properties, firstly the PDS once in contact with the morphological structure of the pulmonary artery did not evoke excessive toxic or inflammatory responses of ECM. Second, it was metabolized, after having completed its favorable strengthening and remodeling action, without leaving a trace. Third, the PDS was easily processable [86-89]. Figure 3. 


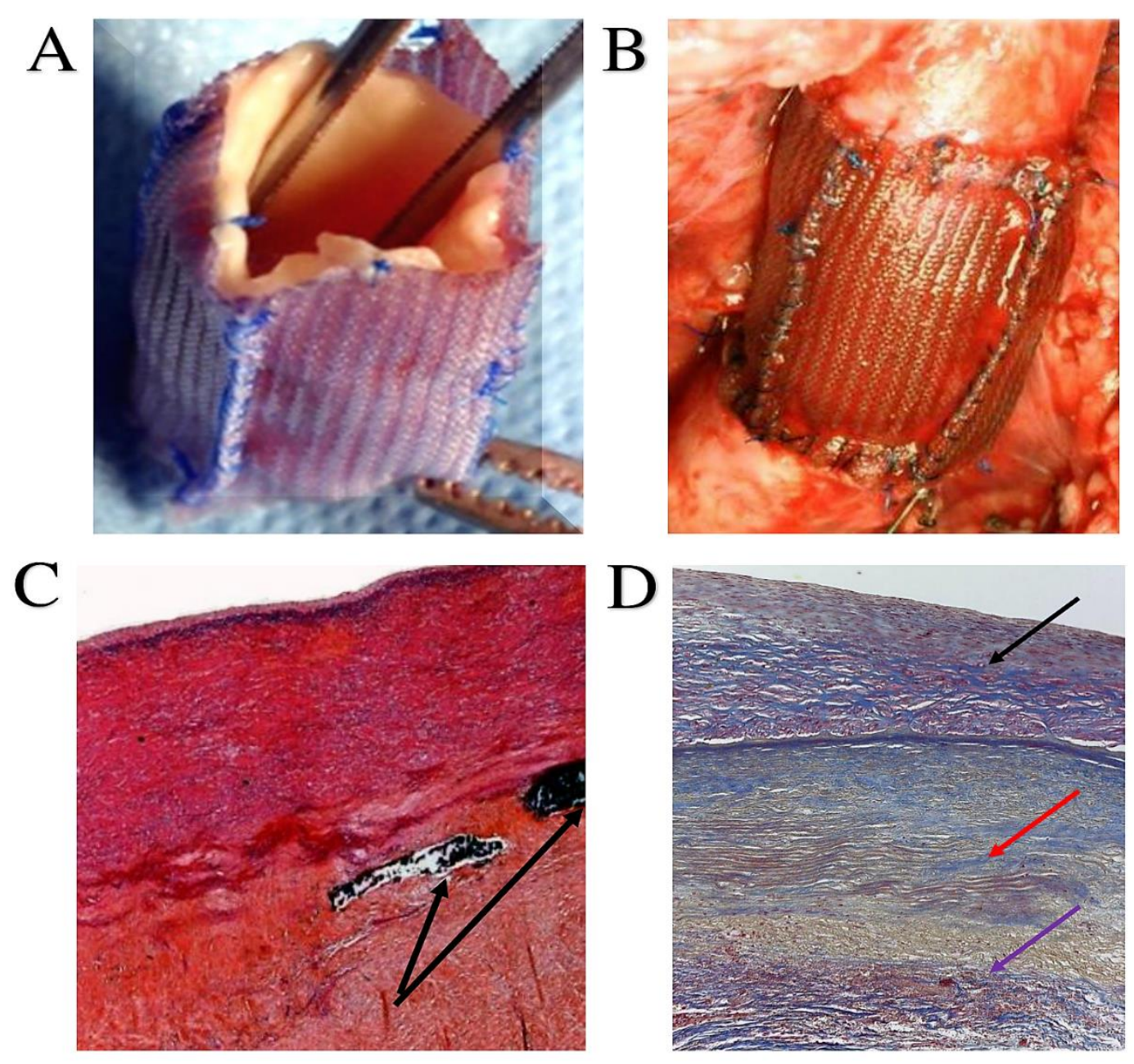

Figure 3. A. Pulmonary autograft reiforced with $15 \mathrm{~mm}$ wide bands of knitted PDS. B: PAimplanted in aortic position. C. The media of pulmonary autograft is perfectly intact. Remnants of the slowly resorbable material of PDS are highlighted in the adventitia (black arrow). D. The histology of PA revealed a complete resorption of the PDS mesh with no damage to the media and an increase in the regenerative connective component especially at advential level. This regenerative tissue was found to be constituted by elastic fibers as you can see at the Masson's Trichrome staining. Black arrow shows the tunica media with normal thickness and no disruption, red arrow reveals elastin fibers and violet arrow highlighted no inflammatory reaction. Abbreviations: PDS, polydioxanone (Ethicon Inc. Johnson \& Johnson); PA, pulmonary autograft

The mechanical properties of the PDS were evaluated according to the application of the material, which was to contain the expansion of the pulmonary artery when it was implanted under systemic pressure, so that the polyester load was automatically distributed on the pulmonary artery tissue as it was degraded, thus reducing the effect of stress shielding $[88,95]$. 


\subsection{Specific characteristic of Polydioxanone}

Polydioxanone (PDS) has about 55\% crystallinity and a glass transition temperature that varies between $-10^{\circ}$ and $0^{\circ} \mathrm{C}$. It features a regular repetition of fundamental units that come together in chains folded into dense regions called crystallites. These join together by means of cross links giving the polymer a high tensile strength and a very high elastic modulus if compared to that of the amorphous analogue. These features are related to the degree of compactness of the polymer. It should be noted that no polymer can be organized into a total crystalline structure, so however high crystallinity may be found inside, partially amorphous regions will always be detectable. PDS is a very viscous, high-medium molecular weight polymer that has a slower biodegradation than those with lower molecular weight and lower viscosity. Notably, temperature plays a fundamental role with regard to material properties $[88,89,94,95]$.

\subsection{Biodegradation molecular mechanisms}

PDS has been degraded primarily due to the loss of molecular weight and the loss of resistance of the material through an initial phase in which the degradation is due to a process of a chemical nature. The biological process and the total removal of the material take place later [86-89].

In detail, the polydioxanone polymer was degraded in two ways: dissolution and chain cleavage. In the case of dissolution, since PDs has hydrophilic domains, it was dissolved during normal physiological processes when solvent molecules, such as $\mathrm{H} 2 \mathrm{O}$ present in pulmonary artery tissue, were absorbed into the polymer and were small enough to occupy the space between the chains of the macromolecules. The $\mathrm{H} 2 \mathrm{O}$ molecules penetrated into the polymer acted as plasticizers, thus making the material more ductile as they reduced the number of secondary bonds between the chains. Furthermore, it is possible that this process could cause an altered crystallinity of the polymer. Both mechanical and thermal properties (e.g., glass transition temperature) can be affected by the absorption of solvent molecules. It was also 
possible that in extreme cases, the chains were soluble enough that few covalent bonds remained between the chains and the polymer that dissolved completely (figure $3 \mathrm{C}$ ) $[89,91$ 94].

Instead, the chain splitting involved the breaking of the primary bonds, rather than the secondary ones. There is a separation between the chain segments at the breaking point of the bond, which has led to a reduction in the molecular weight, which can have, as in the case of dissolution, significant consequences on the mechanical and thermal properties. Chain splitting can occur hydrolytically or by oxidation $[94,95]$.

As regards hydrolysis, the $\mathrm{H} 2 \mathrm{O}$ molecules have penetrated into the implanted material causing the splitting of the molecular bonds between monomers. This condition led to the splitting of the polymer chains into shorter chains. The main factors that produced the extension of PDS hydrolysis were: the reactivity of the functional groups of the main part of the polymer; the extension of the inter-chain links; the increase of the $\mathrm{H} 2 \mathrm{O}$ available for the polymer. We have recorded in the vessel wall segments of non-degraded PDS due to probable reduction of the tissue $\mathrm{H} 2 \mathrm{O}$ content but we cannot establish whether it is secondary to dissolution or hydrolytic cleavage [87-89, 94,95].

In the pulmonary artery wall, PDS was also eliminated by oxidation through the formation of free radicals that attack and break the covalent bonds that hold the chains together. The main factors influencing oxidation are mostly the reactivity of the functional groups of the main part of the polymer; the extension of the inter-chain links [89, 92-94].

The degradation of polydioxanone occurs through the cleavage of their ester chains. PDS, on the other hand, is split into glycoxylate and excreted in the urine, or converted into glycine and subsequently, like Polyglactin (PGA), transformed into $\mathrm{H} 2 \mathrm{O}$ and carbon dioxide. In any case, both PGA and PDS follow the same final cycle (from pyruvate towards) as PLA. The degradation time, as already mentioned, depends on the porosity of the copolymer, on the 
crystallinity, and on the molecular weight. Polyglactin and PDS materials can be selected as early- and late-resorbable materials, respectively, with an absorption time of $\sim 21$ days for the PG, and $\sim 6$ months for the PDS. In addition, PDS is used as the preferred suture material in pediatric cardiac surgery [86-89, 94,95].

\subsection{The use of Polydioxanone as crosslinked prosthetics: when and how}

The pulmonary valve and trunk or the pulmonary autograft (PA i. e) may be used to treat aortic valve disease, however the pulmonary conduit is exposed to progressive expansion when it is implanted under the systemic pressure regimen. This operation was firstly executed by Donald Ross in 1967 and for this reason it is named Ross procedure (figure 3 A, B) [96].

The checks performed by our clinical teams have confirmed a trend towards dilatation of pulmonary autograft after the Ross procedure leading for a potentially risk of reoperation. The use of dacron as an external reinforcement is a choice adopted by many surgeons, however we have never been in favor of adopting it. We preferred to maintain the characteristics of the PA as living tissue while trying to induce remodeling of the pulmonary conduit [97-102].

The dacron, for various reasons, can not be considered suitable material for this reinforcement and the late outcomes of the use of this synthetic materials are increasingly revealing its limitations at both the clinical and biological level. Infact the dacron used by many surgeons in many institutions is unable to growth and fail to match the demanding need of a growing structure such as the pulmonary autograft especially when it is implanted in the pediatric population. Secondly, vascular compliance is poor and it has been estimated that Dacron has a stiffness that is 24 times greater than native aorta [86-88,95]. This would imply the loss of elastomechanical properties and windkessel function of the neoaortic root with retrograde effect on the aortic valve, crowding its leaflet and eventually leading to its incompetence. Lastly, synthetic materials are able to induce a strong inflammatory reaction impairing PA graft 
viability and interfering with the arterialization process. This concept has been recently stressed in the literature which is increasingly pointing at the graft viability and at its biological features as one of the main reasons of the clinical success of the Ross operation $[95,103,104]$.

From a histopathological point of view the use of external dacron reinforcement was accompained with remarkable thinning of the pulmonary artery wall leading to intimal denudation and multiple medial disruptions. Dacron meshes can migrate inside the vessel wall. We recorded a high percentage of disseminated collagen fibers associated with peculiar histological alterations that showed a conspicuous inflammatory infiltrate (figure 3 D) [87$89,91,92]$.

On the contrary pathological analysis performed after the use of resorbable polydioxanone to reinforce pulmonary artery revealed a partial resorption of the polyester, recording a preserved endothelial lining. This evidence suggested to confirm the absence of intimal tearing under pressure load. In addition, a medial thickening with thoroughly arranged fibromuscular cells mixed to abundant neo-formed connective tissue was identified (figure $3 \mathrm{D}$ ). Of note, using the polydioxanone the MMP-9 was detected to be overexpressed once the polyester was integrated into the ECM so to point out an ongoing matrix remodeling process $[88,94]$. The collagen architecture appeared well organized with a compact density and distribution in the elastic region of the pulmonary artery. Taken together, these results concretely suggest a shift towards a process of elastic remodeling and neo-arterialization. In confirmation of these findings, it was possible to note the presence of a scarce inflammatory infiltrate with rare macrophages or monocytes that colonized the reinforced arterial wall. Pathoanatomical evidence reliably suggested that the biomaterial did not elicit an exuberant foreign body inflammatory reaction over time $[87-89,91,92,94]$.

We induced a neoarterialization of the PA which was placed in the aortic position and therefore exposed to a regimen of systemic pressure. In the pulmonary artery we reproduced the 
physiological condition according to which, under the effect of systemic pressure, a conversion of the elastic tension into elastic potential energy occurred. The previously reported histological evidences demonstrated that during the reabsorption process of a scaffold constituted by PDS and applied to the PA, a remodeling phenomenon of the vessel wall occurred, resulting in a denser connective architecture of the tunica media with an increase in its elastic component (figure 3 A-C) [86-88,94].

The bioresorbable polyester external prosthesis increased the surface of the neoaorta and, at the same time, was reabsorbed within the PA, in order to modify both the cohesion forces and the elastic characteristics of the membrane. This process was possible for the molecular structure of PDS which is characterized by the repetition of fundamental units with a crystallinity of about 55\%, capable of increasing the intramolecular cohesion forces (figure 4 A, B) $[88,95,97,98]$.
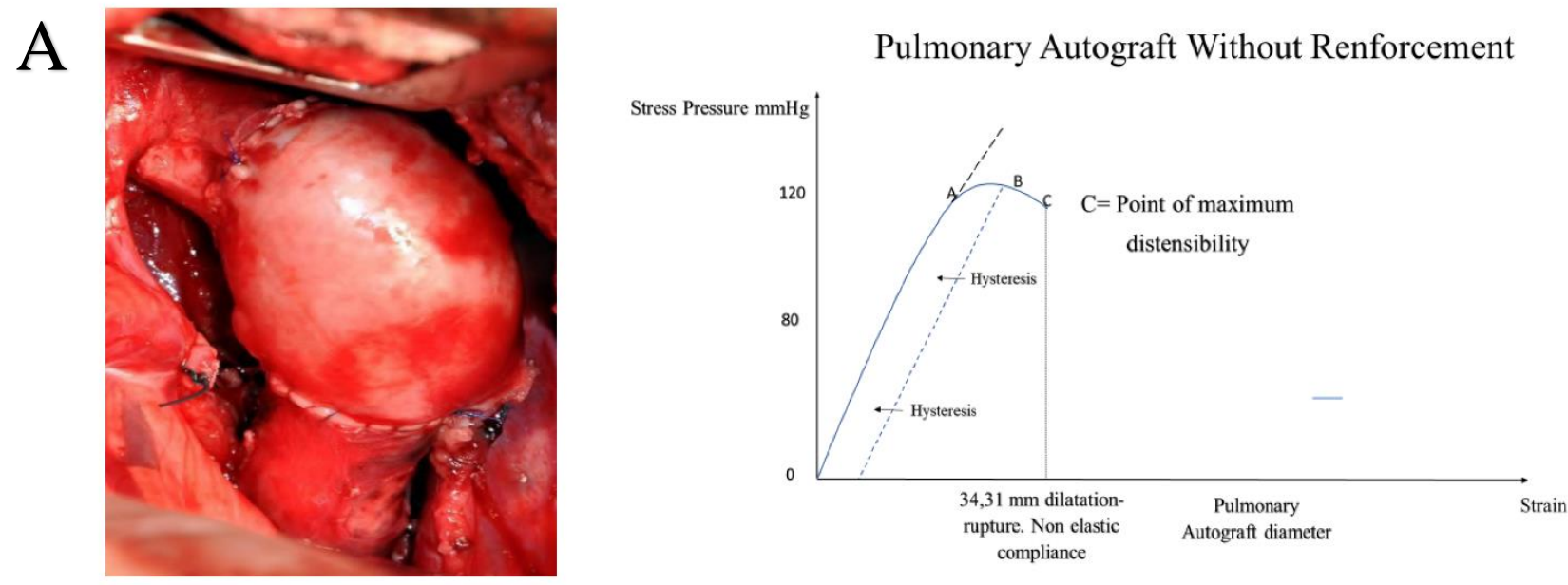

B 

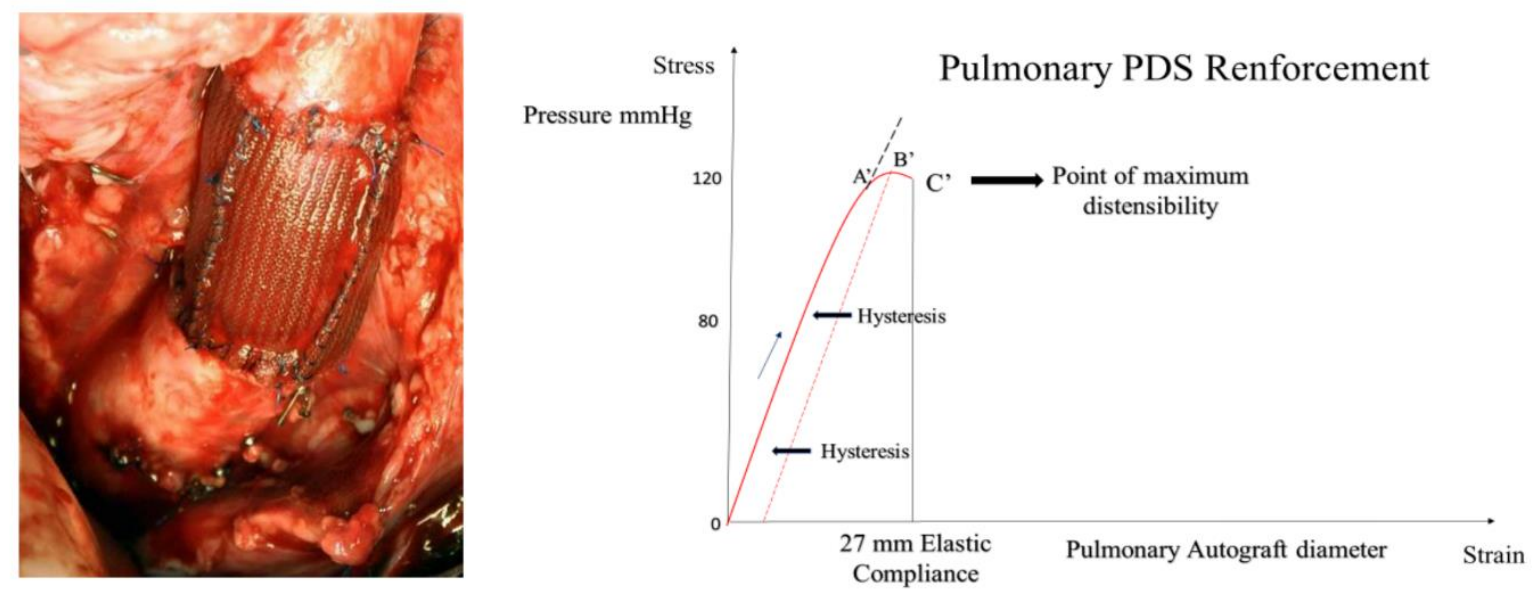

Figure 4. Shows the ability of resorbable hydrogels such as PDF to modify the elastomeccanic function of the vessel wall. The application of a bioresorbable reinforcement with function as hydrogel is able to modify the behavior of the curve of distensible materials as the PA wall, obtaining an increase in their elastic properties. This is observed in the curve as the shift of A (pannel A left) toward A' (pannel B left) with increased elasticity and compliance. The maximum distensibility point $C$ toward $C^{\prime}$, as the reinforcement effectively prevented massive dilation. This provokes a reduction in the critical area determined by the fall of the curve (pannel B left). The potential elastic energy depends on the extension of the surface and on the composition of the material constituting the cylinder including the intramolecular cohesion forces. We demonstrated histologically that during the resorption process of a PDS scaffold applied to the PA (panel B), a remodeling process of the vessel wall occurs, resulting in a more dense connective architecture of the tunica media with an increase in its elastic component.

\section{Conclusions}

Hydrogel formulations have recently been regarded as novel delivery opportunities. Despite this, they have been studied for long and are conquering vast clinical fields. Anticancer therapies are one of the best applications, due to their severe side effects including cardiovascular toxicities, namely heart failure and myocarditis. After preclinical studies implementations, trials will be held, due to the extraordinary results obtained from in vitro and animal in vivo experimentations. 


\section{Abbreviations}

PEG: poly ethylene-glycols

CAR-T: chimeric antigen receptor $\mathrm{T}$

ECG: electrocardiogram

HF: heart failure

HER2: human epidermal receptor 2

VEGF: vascular endothelial growth factor

mTOR: (mechanistic target of rapamycin)

BCR-ABL1: Breakpoint Cluster Region-ABL1

BTK: Bruton's tyrosine kinase

ALK: Anaplastic lymphoma kinase

BRAF: Rapidly Accelerated Fibrosarcoma-B

MAPKK: Mitogen-activated protein kinase kinase

NOD/SCID: nonobese diabetic/severe combined immunodeficiency

PCR: polymerase chain reaction

ELISA: enzyme-linked immunoassay

AAV: adeno-associated virus

ECM: extraceullular matrix

i.v.: intravenous

c-PGA-MA: maleimide-modified c-polyglutamic acid

4-arm PEG-SH: thiol end-functionalized 4-arm polyethylene glycol

GM-CSF: granulocyte-macrophage colony stimulating factor

DCs: endritic cells

IgGs: immunoglobulin Gs

IFN- $\gamma$ : inerferon- $\gamma$ 
IL-4: interleukin-4

TNF- $\alpha$ : tumor necrosis factor- $\alpha$

TSPBA: N3-tetramethylpropane-1,3-diaminium

RCA: rolling circle amplification

ROS: reactive oxygen species

CTLA4: cytotoxic T-lymphocyte antigen 4

PD-1: programmed death 1

DNA: deoxyribonucleic acid

PDS: Polydioxanone

PA: pulmonary autograft

PGA: Polyglactin

MMP-9: matrix metalloproteinase-9

Author Contributions: Conceptualization, FN and AI; methodology, FN and AI.; software, $\mathrm{AI}$ and $\mathrm{CC}$; ; validation, $\mathrm{FN}, \mathrm{AI}, \mathrm{CC}$ and $\mathrm{MC}$; formal analysis, $\mathrm{FN}$ and $\mathrm{AI}$; investigation, $\mathrm{FN}$, $\mathrm{AI}$ and $\mathrm{CC}$; data curation, FN AI and $\mathrm{CC}$; writing — original draft preparation, FN and AI; writing - review and editing, FN, AI, CC and MC; visualization, FN and AI; supervision, FN, AI, CC and MC. All authors have read and agreed to the published ver-sion of the manuscript

Funding: This research received no external funding

Institutional Review Board Statement: Not applicable.

Informed Consent Statement: Not applicable.

Data Availability Statement:

Conflicts of Interest: The authors declare no conflict of interest 


\section{References}

1. Braithwaite D, Tammemagi CM, Moore DH, Ozanne EM, Hiatt RA, Belkora J, et al. Hypertension is an independent predictor of survival disparity between African-American and white breast cancer patients. Int J Cancer. 2009;124(5):1213-9.

2. Zhong S, Yu D, Zhang X, Chen X, Yang S, Tang J, et al. beta-Blocker use and mortality in cancer patients: systematic review and meta-analysis of observational studies. Eur J Cancer Prev. 2015. Epub 2015/09/05.

3. Nolan MT, Plana JC, Thavendiranathan P, Shaw L, Si L, Marwick TH. Cost-effectiveness of strain-targeted cardioprotection for prevention of chemotherapy-induced cardiotoxicity. Int J Cardiol. 2016 Jun 1; 212:336-45.

4. Chavez-MacGregor M, Zhang N, Buchholz TA, Zhang Y, Niu J, Elting L, Smith BD, Hortobagyi GN, Giordano SH. Trastuzumab-related cardiotoxicity among older patients with breast cancer. J Clin Oncol. 2013 Nov 20;31(33):4222-8.

5. Ventura GJ. Cardiotoxicity of epirubicin versus doxorubicin: cost and clinical results. J Clin Oncol. 2005 Apr 20;23(12):2873; author reply 2873-4.

6. Padegimas A, Clasen S, Ky B. Cardioprotective strategies to prevent breast cancer therapyinduced cardiotoxicity. Trends Cardiovasc Med. 2020 Jan;30(1):22-28.

7. Barbar T, Mahmood SS, Liu JE. Cardiomyopathy Prevention in Cancer Patients. Cardiol Clin. 2019 Nov;37(4):441-447.

8. Fojtu M, Gumulec J, Stracina T, Raudenska M, Skotakova A, Vaculovicova M, Adam V, Babula P, Novakova M, Masarik M. Reduction of Doxorubicin-Induced Cardiotoxicity Using Nanocarriers: A Review. Curr Drug Metab. 2017;18(3):237-263.

9. Monahan DS, Almas T, Wyile R, Cheema FH, Duffy GP, Hameed A. Towards the use of localised delivery strategies to counteract cancer therapy-induced cardiotoxicities. Drug Deliv Transl Res. 2021 Jan 15. doi: 10.1007/s13346-020-00885-3. 
10. Saludas L, Pascual-Gil S, Prósper F, Garbayo E, Blanco-Prieto M. Hydrogel based approaches for cardiac tissue engineering. Int J Pharm. 2017 May 25;523(2):454-475. doi: 10.1016/j.ijpharm.2016.10.061. Epub 2016 Oct 29. PMID: 27989830.

11. Pang C, Ibrahim A, Bulstrode NW, Ferretti P. An overview of the therapeutic potential of regenerative medicine in cutaneous wound healing. Int Wound J. 2017;14(3):450-459. doi:10.1111/iwj.12735

12. Gupta S, Mohapatra DP, Chittoria RK, et al. Human Skin Allograft: Is it a Viable Option in Management of Burn Patients? J Cutan Aesthet Surg. 2019;12(2):132-135. doi: 10.4103/JCAS.JCAS_83_18

13. Muzzio N, Moya S, Romero G. Multifunctional Scaffolds and Synergistic Strategies in Tissue Engineering and Regenerative Medicine. Pharmaceutics. 2021;13(6):792. Published 2021 May 26. doi:10.3390/pharmaceutics13060792

14. El-Sherbiny IM, Yacoub MH. Hydrogel scaffolds for tissue engineering: Progress and challenges. Glob Cardiol Sci Pract. 2013;2013(3):316-342. Published 2013 Nov 1. doi:10.5339/gcsp.2013.38

15. Yue S, He H, Li B, Hou T. Hydrogel as a Biomaterial for Bone Tissue Engineering: A Review. Nanomaterials $\quad$ (Basel). 2020;10(8):1511. Published $2020 \quad$ Jul 31. doi:10.3390/nano10081511

16. Ahmed EM. Hydrogel: Preparation, characterization, and applications: A review. J Adv Res. 2015 Mar;6(2):105-21. doi: 10.1016/j.jare.2013.07.006. Epub 2013 Jul 18. PMID: 25750745; PMCID: PMC4348459.

17. Lakshmanan, R., Krishnan, U.M., Sethuraman, S., 2013. Polymeric scaffold aided stem cell therapeutics for cardiac muscle repair and regeneration. Macromol. Biosci. 13, 1119-1134. 
18. Sepantafar, M., Maheronnaghsh, R., Mohammadi, H., Rajabi-Zeleti, S., Annabi, N., Aghdami, N., Baharvand, H., 2016. Stem cells and injectable hydrogels: synergistic therapeutics in myocardial repair. Biotechnol. Adv. 34, 362-379.

19. Zhu, J., Marchant, R.E., 2011. Design properties of hydrogel tissue-engineering scaffolds. Expert Rev. Med. Devices 8, 607-626.

20. 1 Ruvinov, E., Cohen, S., 2016. Alginate biomaterial for the treatment of myocardial infarction Progress, translational strategies, and clinical outlook: from ocean algae to patient bedside. Adv. Drug Deliv. Rev. 96, 54-76.

21. Jawad, H., Lyon, A.R., Harding, S.E., Ali, N.N., Boccaccini, A.R., 2008. Myocardial tissue engineering. Br. Med. Bull. 87, 31-47.

22. Asti, A., Gioglio, L., 2014. Natural and synthetic biodegradable polymers: different scaffolds for cell expansion and tissue formation. Int. J. Artif. Organs 37, 187-

23. Nair, L.S., Laurencin, C.T., 2006. Polymers as biomaterials for tissue engineering and controlled drug delivery. Adv. Biochem. Eng. Biotechnol. 102, 47-90.

24. Klouda, L., 2015. Thermoresponsive hydrogels in biomedical applications: a sevenyear update. Eur. J. Pharm. Biopharm. 97, 338-349.

25. Ravichandran, R., Venugopal, J.R., Sundarrajan, S., Mukherjee, S., Ramakrishna, S., 2012. Minimally invasive cell-seeded biomaterial systems for injectable/ epicardial implantation in ischemic heart disease. Int. J. Nanomed. 7, 5969.

26. Samchenko, Y., Ulberg, Z., Korotych, O., 2011. Multipurpose smart hydrogel systems.Adv. Colloid Interface Sci. 168, 247-262.

27. Ebara, M., Kotsuchibashi, Y., Uto, K., Aoyagi, T., Kim, Y.-J., Narain, R., Idota, N., Hoffman, J.M., 2014. Smart Hydrogels 9-65.

28. Yang, L., Chu, J.S., Fix, J.A., 2002. Colon-specific drug delivery: new approaches and in vitro/in vivo evaluation. Int. J. Pharm. 235, 1-15. 
29. Sasaki, Y., Akiyoshi, K., 2010. Nanogel engineering for new nanobiomaterials: from chaperoning engineering to biomedical applications. Chem. Rec. 10, 366-376. Schulman, I.H., Hare, J.M., 2012. Key developments in stem cell therapy in cardiology. Regener. Med. 7, 1724.

30. M. S. Rehmann and A. M. Kloxin, "Tunable and dynamic soft materials for threedimensional cell culture," Soft Matter 9(29), 6737-6746 (2013).

31. X. Guan, M. Avci-Adali, E. Alarcin, H. Cheng, S. S. Kashaf, Y. Li, A. Chawla,H. L. Jang, and A. Khademhosseini, "Development of hydrogels for regenerative engineering," Biotechnol. J. 12(5), 1600394 (2017).

32. Oh, J.K., Drumright, R., Siegwart, D.J., Matyjaszewski, K., 2008. The development of microgels/nanogels for drug delivery applications. Prog. Polym. Sci. 33, 448477.

33. Pourshahrestani S, Zeimaran E, Kadri NA, Mutlu N, Boccaccini AR. Polymeric Hydrogel Systems as Emerging Biomaterial Platforms to Enable Hemostasis and Wound Healing. Adv Healthc Mater. 2020 Oct;9(20):e2000905. doi: 10.1002/adhm.202000905. Epub 2020 Sep 16. PMID: 32940025.

34. Gao L, Chen J, Feng W, Song Q, Huo J, Yu L, Liu N, Wang T , Li P, Huang W . A multifunctional shape-adaptive and biodegradable hydrogel with hemorrhage control and broad-spectrum antimicrobial activity for wound healing. Biomater Sci. 2020 Dec 15;8(24):6930-6945. doi: 10.1039/d0bm00800a. PMID: 32964904.

35. B. P. Chan and K. W. Leong, "Scaffolding in tissue engineering: General approaches and tissue-specific considerations,” Eur. Spine J. 17(Suppl 4), 467-479 (2008).

36. Jackson SE, Chester JD. Personalised cancer medicine. Int J Cancer. 2015 Jul 15;137(2):262-6. doi: 10.1002/ijc.28940.

37. Kim ES, Pandya KJ. Advances in personalized therapy for lung cancer. Expert Opin Med Diagn. 2013 Sep;7(5):475-85. doi: 10.1517/17530059.2013.826645. 
38. De Mattos-Arruda L, Blanco-Heredia J, Aguilar-Gurrieri C, Carrillo J, Blanco J. New emerging targets in cancer immunotherapy: the role of neoantigens. ESMO Open. 2020 Apr;4(Suppl 3):e000684. doi: 10.1136/esmoopen-2020-000684.

39. Jain KK. Role of nanobiotechnology in developing personalized medicine for cancer. Technol Cancer Res Treat. 2005 Dec;4(6):645-50. doi: 10.1177/153303460500400608.

40. Grassi L, Alfonsi R, Francescangeli F, Signore M, De Angelis ML, Addario A, Costantini M, Flex E, Ciolfi A, Pizzi S, Bruselles A, Pallocca M, Simone G, Haoui M, Falchi M, Milella M, Sentinelli S, Di Matteo P, Stellacci E, Gallucci M, Muto G, Tartaglia M, De Maria R, Bonci D. Organoids as a new model for improving regenerative medicine and cancer personalized therapy in renal diseases. Cell Death Dis. 2019 Feb 27;10(3):201. doi: 10.1038/s41419-019$1453-0$.

41. Garbayo E, Pascual-Gil S, Rodríguez-Nogales C, Saludas L, Estella-Hermoso de Mendoza A, Blanco-Prieto MJ. Nanomedicine and drug delivery systems in cancer and regenerative medicine. Wiley Interdiscip Rev Nanomed Nanobiotechnol. 2020 Sep;12(5):e1637. doi: 10.1002/wnan.1637.

42. Yang Y. Cancer immunotherapy: harnessing the immune system to battle cancer. J Clin Invest. 2015 Sep;125(9):3335-7. doi: 10.1172/JCI83871.

43. Asnani A. Cardiotoxicity of Immunotherapy: Incidence, Diagnosis, and Management. Curr Oncol Rep. 2018 Apr 11;20(6):44. doi: 10.1007/s11912-018-0690-1.

44. Dal'bo N, Patel R, Parikh R, Shah SP, Guha A, Dani SS, Ganatra S. Cardiotoxicity of Contemporary Anticancer Immunotherapy. Curr Treat Options Cardiovasc Med. 2020;22(12):62. doi: 10.1007/s11936-020-00867-1.

45. Rochette L, Guenancia C, Gudjoncik A, Hachet O, Zeller M, Cottin Y, Vergely C. Anthracyclines/trastuzumab: new aspects of cardiotoxicity and molecular mechanisms. Trends Pharmacol Sci. 2015 Jun;36(6):326-48. doi: 10.1016/j.tips.2015.03.005. 
46. Wenningmann N, Knapp M, Ande A, Vaidya TR, Ait-Oudhia S. Insights into Doxorubicininduced Cardiotoxicity: Molecular Mechanisms, Preventive Strategies, and Early Monitoring. Mol Pharmacol. 2019 Aug;96(2):219-232. doi: 10.1124/mol.119.115725.

47. Raschi E, Vasina V, Ursino MG, Boriani G, Martoni A, De Ponti F. Anticancer drugs and cardiotoxicity: Insights and perspectives in the era of targeted therapy. Pharmacol Ther. 2010 Feb;125(2):196-218. doi: 10.1016/j.pharmthera.2009.10.002.

48. Ganatra S, Neilan TG. Immune Checkpoint Inhibitor-Associated Myocarditis. Oncologist. 2018 Aug;23(8):879-886. doi: 10.1634/theoncologist.2018-0130.

49. Salem JE, Manouchehri A, Moey M, Lebrun-Vignes B, Bastarache L, Pariente A, Gobert A, Spano JP, Balko JM, Bonaca MP, Roden DM, Johnson DB, Moslehi JJ. Cardiovascular toxicities associated with immune checkpoint inhibitors: an observational, retrospective, pharmacovigilance study. Lancet Oncol. 2018 Dec;19(12):1579-1589. doi: 10.1016/S14702045(18)30608-9.

50. Stein-Merlob AF, Rothberg MV, Holman P, Yang EH. Immunotherapy-Associated Cardiotoxicity of Immune Checkpoint Inhibitors and Chimeric Antigen Receptor T Cell Therapy: Diagnostic and Management Challenges and Strategies. Curr Cardiol Rep. 2021 Jan 22;23(3):11. doi: 10.1007/s11886-021-01440-3.

51. National Center for Biotechnology Information (2021). PubChem Compound Summary for $\begin{array}{llll}\text { CID 31703, } & \text { Doxorubicin. } & \text { Retrieved } & \text { June }\end{array}$ from https://pubchem.ncbi.nlm.nih.gov/compound/Doxorubicin.

52. Lefrak EA, Pitha J, Rosenheim S, Gottlieb JA. A clinicopathologic analysis of adriamycin cardiotoxicity. Cancer. 1973 Aug;32(2):302-14.

53. Lishner M, Elis A, Ravid M. Late doxorubicin cardiotoxicity. Anticancer Drugs. 1992 Aug;3(4):367-9. 
54. Mitry MA, Laurent D, Keith BL, Sira E, Eisenberg CA, Eisenberg LM, Joshi S, Gupte S, Edwards JG. Accelerated cardiomyocyte senescence contributes to late-onset doxorubicininduced cardiotoxicity. Am J Physiol Cell Physiol. 2020 Feb 1;318(2):C380-C391.

55. Gottlieb SL, Edmiston WA Jr, Haywood LJ. Late, late doxorubicin cardiotoxicity. Chest. 1980 Dec;78(6):880-2.

56. Hallman BE, Hauck ML, Williams LE, Hess PR, Suter SE. Incidence and risk factors associated with development of clinical cardiotoxicity in dogs receiving doxorubicin. $\mathrm{J}$ Vet Intern Med. 2019 Mar;33(2):783-791.

57. Von Hoff DD, Layard MW, Basa P, Davis HL Jr, Von Hoff AL, Rozencweig M, Muggia FM. Risk factors for doxorubicin-induced congestive heart failure. Ann Intern Med. 1979 Nov;91(5):710-7.

58. Iqubal A, Iqubal MK, Sharma S, Ansari MA, Najmi AK, Ali SM, Ali J, Haque SE. Molecular mechanism involved in cyclophosphamide-induced cardiotoxicity: Old drug with a new vision. Life Sci. 2019 Feb 1;218:112-131. doi: 10.1016/j.lfs.2018.12.018.

59. Kumar S, Gupta RK, Samal N. Cyclophosphamide cardiotoxicity. Natl Med J India. 1992 Jan-Feb;5(1):17-9. PMID: 1304238.

60. von Bernuth G, Adam D, Hofstetter R, Lang D, Mohr W, Kohne E, Niethammer D. Cyclophosphamide cardiotoxicity. Eur J Pediatr. 1980 Jun;134(1):87-90. doi: 10.1007/BF00442410.

61. Sarosiek T, Morawski P. Trastuzumab and its biosimilars [Trastuzumab and its biosimilars]. Pol Merkur Lekarski. 2018 May 25;44(263):253-257.

62. Blaes AH, Dang C. Trastuzumab: Weighing the Benefits and the Risks. J Natl Cancer Inst. 2020 Dec 14;112(12):1181-1182. doi: 10.1093/jnci/djaa055. 
63. Nemeth BT, Varga ZV, Wu WJ, Pacher P. Trastuzumab cardiotoxicity: from clinical trials to experimental studies. $\mathrm{Br} \quad \mathrm{J}$ Pharmacol. 2017 Nov;174(21):3727-3748. doi: 10.1111/bph.13643.

64. Barish R, Gates E, Barac A. Trastuzumab-Induced Cardiomyopathy. Cardiol Clin. 2019 Nov;37(4):407-418. doi: 10.1016/j.ccl.2019.07.005.

65. Florido R, Smith KL, Cuomo KK, Russell SD. Cardiotoxicity From Human Epidermal Growth Factor Receptor-2 (HER2) Targeted Therapies. J Am Heart Assoc. 2017;6(9): e006915. 66. Arroyo-Crespo JJ, Armi..n A, Charbonnier D, Balzano-Nogueira L, Huertas-L.pez F, Mart. C, et al. Tumor microenvironment-targeted poly-L-glutamic acid-based combination conjugate for enhanced triple negative breast cancer treatment. Biomaterials [Internet]. 2018;186:8-21. 67. Mazzucchelli S, Bellini M, Fiandra L, Truffi M, Rizzuto MA, Sorrentino L, et al. Nanometronomic treatment of 4T1 breast

cancer with nanocaged doxorubicin prevents drug resistance and circumvents cardiotoxicity. Oncotarget. 2017;8(5):8383-96.

68. Bansal N, Adams MJ, Ganatra S, Colan SD, Aggarwal S, Steiner R, Amdani S, Lipshultz ER, Lipshultz SE. Strategies to prevent anthracycline-induced cardiotoxicity in cancer survivors. Cardiooncology. 2019 Dec 2;5:18.

69. Toffoli G, Hadla M, Corona G, Caligiuri I, Palazzolo S, Semeraro S, et al. Exosomal doxorubicin reduces the cardiac toxicity of doxorubicin. Nanomedicine (Lond). 2015;10(19):2963-71.

70. Hicks MJ, Funato K, Wang L, Aronowitz E, Dyke JP, Ballon DJ, Havlicek DF, Frenk EZ, De BP, Chiuchiolo MJ, Sondhi D, Hackett NR, Kaminsky SM, Tabar V, Crystal RG. Genetic modification of neurons to express bevacizumab for local anti-angiogenesis treatment of glioblastoma. Cancer Gene Ther. 2015 Jan;22(1):1-8. doi: 10.1038/cgt.2014.58. 
71. Watanabe M, Boyer JL, Crystal RG. AAVrh.10-mediated genetic delivery of bevacizumab to the pleura to provide local anti-VEGF to suppress growth of metastatic lung tumors. Gene Ther. 2010 Aug;17(8):1042-51. doi: 10.1038/gt.2010.87.

72. Jain RK. (1990). Physiological barriers to delivery of monoclonal antibodies and other macromolecules in tumors. Cancer Res 50:814s-9s.

73. Magzoub M, Jin S, Verkman AS. (2008). Enhanced macromolecule diffusion deep in tumors after enzymatic digestion of extracellular matrix collagen and its associated proteoglycan decorin. Faseb J 22:276-84.

74. Marcucci F, Bellone M, Rumio C, et al. (2013). Approaches to improve tumor accumulation and interactions between monoclonal antibodies and immune cells. MAbs 5:34-46.

75. Shin TH, Sung ES, Kim YJ, et al. (2014). Enhancement of the tumorpenetration of monoclonal antibody by fusion of a neuropilin-targeting peptide improves the antitumor efficacy. Mol Cancer Ther

$13: 651-61$.

76. Pan A, Wang Z, Chen B, Dai W, Zhang H, He B, Wang X, Wang Y, Zhang Q. Localized co-delivery of collagenase and trastuzumab by thermosensitive hydrogels for enhanced antitumor efficacy in human breast xenograft. Drug Deliv. 2018 Nov;25(1):1495-1503. doi: 10.1080/10717544.2018.1474971.

77. Lo YW, Sheu MT, Chiang WH, Chiu YL, Tu CM, Wang WY, Wu MH, Wang YC, Lu M, Ho HO. In situ chemically crosslinked injectable hydrogels for the subcutaneous delivery of trastuzumab to treat breast cancer. Acta Biomater. 2019 Mar 1; 86:280-290. doi: 10.1016/j.actbio.2019.01.003.

78. Xu K, Lee F, Gao S, Tan M-H, Kurisawa M. Hyaluronidaseincorporated hyaluronic acidtyramine hydrogels for the sustained release of trastuzumab. J Control Release [Internet]. 2015; 216:47-55. 
79. Song H, Yang P, Huang P, Zhang C, Kong D, Wang W. Injectable polypeptide hydrogelbased co-delivery of vaccine and immune checkpoint inhibitors improves tumor immunotherapy. Theranostics. 2019 Apr 12;9(8):2299-2314. doi: 10.7150/thno.30577.

80. Han X, Li H, Zhou D, Chen Z, Gu Z. Local and Targeted Delivery of Immune Checkpoint Blockade Therapeutics. Acc Chem Res. 2020 Nov 17;53(11):2521-2533. doi: 10.1021/acs.accounts.0c00339.

81. Ruan, H.; Hu, Q.; Wen, D.; Chen, Q.; Chen, G.; Lu, Y.; Wang, J.; Cheng, H.; Lu, W.; Gu, Z. A dual-bioresponsive drug-delivery depot for combination of epigenetic modulation and immune checkpoint blockade. Adv. Mater. 2019, 31, 1806957.

82. Yu, S.; Wang, C.; Yu, J.; Wang, J.; Lu, Y.; Zhang, Y.; Zhang, X.; Hu, Q.; Sun, W.; He, C.; et al. Injectable bioresponsive gel depot for enhanced immune checkpoint blockade. Adv. Mater. 2018, 30, 1801527.

83. M. Shahid, S.M. Nimjee, R. Rebekah, R.R. White, C. Richard, R.C. Becker, et al., Aptamers as therapeutics, Annu. Rev. Pharmacol. Toxicol. 57 (2017) 61-79.

84. J. Jiehua, J. Rossi, Aptamers as targeted therapeutics: current potential and challenges, Nat. Rev. Drug Discov. 16 (2017) 181-202.

85. Lee J, Le QV, Yang G, Oh YK. Cas9-edited immune checkpoint blockade PD-1 DNA polyaptamer hydrogel for cancer immunotherapy. Biomaterials. 2019 Oct; 218:119359. doi: 10.1016/j.biomaterials.2019.119359.

86. Nappi F, Spadaccio C, Castaldo C, Di Meglio F, Nurzynska D, Montagnani S, Chello M, Acar C. Reinforcement of the pulmonary artery autograft with a polyglactin and polydioxanone mesh in the Ross operation: experimental study in growing lamb. J Heart Valve Dis 2014; 23 :145-8. 
87. Nappi F, Spadaccio C, Fouret P, Hammoudi N, Chachques JC, Chello M, Acar C. An experimental model of the Ross operation: Development of resorbable reinforcements for pulmonary autografts. J Thorac Cardiovasc Surg. 2015 Apr ;149(4) :1134-42.

88. Nappi F, Spadaccio C, Fraldi M, Montagnani S, Fouret P, Chachques JC, Acar C. A composite semiresorbable armoured scaffold stabilizes pulmonary autograft after the Ross operation: Mr Ross's dream fulfilled. J Thorac Cardiovasc Surg. 2016 Jan;151(1):155-64. e1.

89. Spadaccio C, Montagnani S, Acar C, Nappi F. Introducing bioresorbable scaffolds into the show. A potential adjunct to resuscitate Ross procedure. Int J Cardiol. $2015 ; 190$ :50-2.

90. Nataf P, Guettier C, Bourbon A, Nappi F, Lima L, Dorent R, Pavie A, Gandjbakhch I. Influence of arterial allograft preparation techniques on chronic vascular rejection: a histological study. Transplant Proc. 1996 Oct ;28(5) :2890-2

91. Spadaccio C, Mozetic P, Nappi F, et al. Cells and extracellular matrix interplay in cardiac valve disease: because age matters. Basic Res Cardiol. 2016 Mar ;111(2) :16

92. Spadaccio C, Rainer A, Mozetic P, et al The role of extracellular matrix in age-related conduction disorders: a forgotten player? J Geriatr Cardiol. 2015 Jan;12(1):76-82.

93. Spadaccio C, Nappi F, De Marco F, et al. Implantation of a Poly-L-Lactide GCSFFunctionalized Scaffold in a Model of Chronic Myocardial Infarction. J Cardiovasc Transl Res. 2017 Feb ;10(1) :47-65.

94. Nappi F, Fraldi M, Spadaccio C, Montagnani S, Castaldo C, Chachques JC, Acar C. Biomechanics drive histological wall remodeling of neoaortic root: A mathematical model to study the expression levels of ki 67, metalloprotease, and apoptosis transition. J Biomed Mater Res A. 2016 Nov;104(11):2785-93

95. Nappi F, Carotenuto AR, Di Vito D, Spadaccio C, Acar C, Fraldi M. Stress-shielding, growth and remodeling of pulmonary artery reinforced with copolymer scaffold and transposed into aortic position. Biomech Model Mechanobiol. 2016 Oct ;15(5) :1141-57. 
96. Ross DN. Replacement of aortic and mitral valves with a pulmonary autograft. Lancet 1967 ;2:956-8.

97. Nappi F, Spadaccio C, Acar C, El-Hamamsy I. Lights and Shadows on the Ross Procedure: Biological Solutions for Biological Problems. Semin Thorac Cardiovasc Surg. 2020 Winter ;32(4) :815-822. doi: 10.1053/j.semtcvs.2020.04.006.

98. Nappi F. Biomechanics of Ross Operation: Still So Much to Learn. Semin Thorac Cardiovasc Surg. 2020 Winter ;32(4) :827-828. doi: 10.1053/j.semtcvs.2020.08.015. Epub 2020 Aug 26.

99. Nappi F, Avtaar Singh SS, Spadaccio C, Acar C. Ross operation 23 years after surgery: It should not be a "forgotten" option. J Card Surg. 2020 Mar 1. doi: 10.1111/jocs.14489. [Epub ahead of print]

100. Nappi F, Nenna A, Spadaccio C, Chello M. Pulmonary autograft in aortic position: is everything known? Transl Pediatr. 2017 Jan ;6(1) :11-17.

101. Nappi F, Nenna A, Larobina D et al. Simulating the ideal geometrical and biomechanical parameters of the pulmonary autograft to prevent failure in the Ross operation. Interact Cardiovasc Thorac Surg.2018 Aug 1;27(2):269-276

102. Nappi F, Singh SSA, Bellomo F, Nappi P, Iervolino A, Acar C. The Choice of Pulmonary Autograft in Aortic Valve Surgery: A State-of-the-Art Primer. Biomed Res Int. 2021 Apr 13 ;2021:5547342

103. Nappi F, Carotenuto AR, Cutolo A, Fouret P, Acar C, Chachques JC, Fraldi M. Compliance mismatch and compressive wall stresses drive anomalous remodelling of pulmonary trunks reinforced with Dacron grafts. J Mech Behav Biomed Mater 2016 Oct; 63 :287-302.

104. Spadaccio C, Nappi F, Al-Attar N, Sutherland FW, Acar C, Nenna A, Trombetta M, Chello M, Rainer A. Old Myths, New Concerns: the Long-Term Effects of Ascending Aorta 
Replacement with Dacron Grafts. Not All That Glitters Is Gold. J Cardiovasc Transl Res. 2016 Aug ; $9(4): 334-42$ 